\title{
Ecoturismo na região turística Caminho dos Ipês: conexões entre identidade biofílica e usufruto dos serviços ecossistêmicos
}

\section{Ecotourism in the tourist region Caminho dos Ipês: connections between biophilic identity and use of ecosystem services}

\author{
Simone Mamede, Maristela Benites, José Sabino, Cleber José Rodrigues Alho
}

RESUMO: turismo de contato com a natureza, quando adequadamente planejado e delineado com princípios de sustentabilidade, pode gerar benefícios socioeconômicos e ambientais que resultam na conservação da sociobiodiversidade. Este trabalho teve por objetivo analisar a percepção dos visitantes da rota turística Caminho dos Ipês, Mato Grosso do Sul, Brasil e sua motivação para a prática do ecoturismo nessa região. A investigação foi desenvolvida no período de maio de 2016 a abril de 2017. Para a coleta de dados foi aplicado um formulário semiestruturado que buscou identificar o perfil dos visitantes, os municípios mais visitados, a motivação para a visitação, as práticas consideradas ecoturísticas, os atrativos mais valorizados, os elementos da biodiversidade com os quais tiveram maior afinidade e o comprometimento com a conservação dos locais visitados. Os 118 turistas/excursionistas $(60,3 \%$ mulheres e $39,7 \%$ homens) foram originários de 22 cidades brasileiras e de outros dois países (Argentina e Bélgica). Constatou-se que a capital Campo Grande é uma cidadechave para roteiros integrados de ecoturismo na região devido à localização geográfica, capacidade logística e riqueza em atrativos naturais. Foi registrado que $95 \%$ dos visitantes dessa região turística se consideram comprometidos com a conservação e proteção das áreas visitadas. Entre as motivações para a prática do ecoturismo em áreas naturais constata-se uma convergência entre biofilia e valorização dos serviços ecossistêmicos oferecidos pela natureza. O bem-estar provocado por vivenciar os ambientes naturais foi o motivo mais abordado pelos visitantes para a prática do ecoturismo $(53,4 \%)$, seguido da percepção de sentir-se parte integrante da natureza $(50,8 \%)$. Os participantes afirmaram que suas preferências ao visitarem áreas naturais em geral são: paisagem (59,3\%), água: corredeiras e cachoeiras $(48,3 \%)$, aves $(39,8 \%)$, mamíferos $(27,1 \%)$ e répteis $(16,9 \%)$. No entanto, o que mais os atraíram para a região turística Caminho dos Ipês foram: riqueza de animais silvestres (44,9\%), abundância de água (37,2\%), as características do bioma Cerrado $(36,4 \%)$ e o relevo $(30,5 \%)$. As práticas mais exercidas nos ambientes naturais visitados foram: contemplação $(47,4 \%)$, fotografia $(39 \%)$, observação da vida silvestre $(33 \%)$, caminhada $(33 \%)$ e birdwatching $(18,6 \%)$. Conclui-se que o ecoturismo pode ser uma estratégia positiva para gerar e aprimorar vínculos afetivos com a natureza, bem como para reconhecer e valorizar os serviços ecossistêmicos.

PALAVRAS-CHAVE: Biofilia; Percepção de Visitantes; Turismo Contemplativo; Ambientes Naturais; Mato Grosso do Sul. 


\section{ABSTRACT}

The tourism of contact with nature, when properly planned and outlined with principles of sustainability, can generate socio-economic and environmental benefits that result in conservation of sociobiodiversity. The objective of this work was to analyze the perception of the visitors of the Caminho dos Ipês tourist route, Mato Grosso do Sul, Brazil, and their motivation to practice ecotourism in this region. The research was carried out from May 2016 to April 2017. A semistructured questionnaire survey was applied to collect data, which sought to identify the profile of visitors, the most visited municipality, the motivation for visitation and practices considered ecotourism, the attractions more valued, the elements of biodiversity with which they had greater affinity and the compromise with the conservation of the visited places. The 118 tourists/excursionists $(60.3 \%$ women and $39.7 \%$ men) originated in 22 Brazilian cities and two other countries (Argentina and Belgium). It was found that the capital Campo Grande is a key city for integrated ecotourism itineraries in the region due to its geographic location, logistic capacity and richness in natural attractions. We recorded that $95 \%$ of the visitors of this tourist region consider themselves committed to the conservation and protection of the areas visited. Among the motivations for the practice of ecotourism in natural areas is a convergence between biophilia and appreciation of ecosystem services offered by nature. The wellbeing generated by experiencing natural environments was the reason most approached by visitors for the practice of ecotourism (53.4\%), followed by the perception of pertencing of nature $(50.8 \%)$. The participants stated that their preferences when visiting natural areas in general are: landscape (59.3\%), water: rapids waters and waterfalls $(48.3 \%)$, birds $(39.8 \%)$, mammals $(27.1 \%)$ and reptiles (16.9\%). However, what attracted them to the Caminho dos Ipês region were: wild animal wealth (44.9\%), abundance of water $(37.2 \%)$, characteristics of the Cerrado biome (36.4\%) and relief $(30.5 \%)$. The most practiced practices in the natural environments visited were: contemplation (47.4\%), photography (39\%), wildlife observation (33\%), trekking (33\%) and birdwatching (18.6\%). It is concluded that ecotourism can be a positive strategy to generate and improve affective bonds with nature, as well as to recognize and value ecosystem services.

KEYWORDS: Biophilia; Visitor Perceptions; Contemplative Tourism; Natural Environments; Mato Grosso do Sul.

\section{Introdução}

Nas últimas décadas, a descaracterização dos ambientes naturais tem assumido ritmo acelerado e sem precedentes. Parte dessa alteração ambiental deriva do julgamento errôneo e da crença no mito da inesgotabilidade dos recursos naturais que acarretam o uso insustentável. Paradoxalmente, ainda que essa visão seja persistente na sociedade e, até certo ponto, hegemônica, o interesse por ambientes naturais tem crescido à medida que suas extensões diminuem ao redor do planeta (SABINO et al., 2012). Tal fenômeno não é isolado, visto que em todas as regiões do mundo é possível encontrar pessoas, grupos sociais, entidades e instituições 
preocupados e dispostos a buscar soluções contra o desaparecimento dos ambientes naturais e suas espécies nativas (MENDONÇA; NEIMAN, 2002; DÍAS et al., 2006; MACE et al., 2012).

A importância da biodiversidade para o bem-estar e a saúde humana só ganhou maior destaque quando o processo de perda da diversidade biológica alertou para a necessidade da conservação e do uso racional dos recursos vivos, com proteção ao fluxo de serviços dos ecossistemas naturais (WILSON, 1997; ALHO, 2012), os quais devem estar em disponibilidade adequada e satisfatória a partir de sua estabilidade ecológica e dinâmica natural. Com isso, setores do turismo como o Ecoturismo têm crescido de forma expressiva.

O conceito de Ecoturismo é um dos mais debatidos dentro do turismo, especialmente entre a academia e o mercado, desde sua concepção original até as diversas práticas e segmentos estabelecidos. As variações de significado permitiram que muitas atividades turísticas definidas por segmentos diversos, mas com interesses específicos em sua prática, pudessem ser colocadas sob tal 'guarda-chuva' ou conceito geral de ecoturismo. Para Hintze (2009), a proposta do ecoturismo é unir o ambientalismo - com abordagens delicadas nos dias atuais, como a questão da conservação do meio ambiente, da responsabilidade social junto às comunidades envolvidas e da educação ambiental - ao turismo que se dá pela exploração comercial de lugares, comunidades e tradições, realizado em momentos de lazer e descontração dos turistas.

Regulação climática, pureza do ar e belezas naturais têm auferido altos valores econômicos devido aos conglomerados urbanos sempre crescentes e às dificuldades de fruição, por todos, de um estilo de vida natural (BENI, 2003). Seja para descoberta de novos lugares, seja para fim específico de contato com a natureza em busca de experiências vivenciais para enriquecimento humano e valorização da sociobiodiversidade, a bem da verdade é que a sociedade tem buscado motivação, por meio do turismo, para fruição da natureza no seu tempo livre.

Encontrar explicações epistemológicas para motivação não é tarefa simples, mas sua compreensão pode elucidar processos mais internos, de base fisiológica, que transcendem apenas a análise psicológica. Em outras palavras, descobrir ou ao menos encontrar a lógica capaz de mover o ser humano para uma ação e tomada de decisões requer um olhar multi e transdisciplinar. Motivação existe dentro de cada indivíduo e se dinamiza pelas necessidades humanas. Maslow (1954) desenvolveu uma teoria tomando como base as necessidades humanas. Para ele, tais necessidades estão organizadas hierarquicamente e a busca para satisfazê-las é o que motiva o ser humano a tomar decisões e a fazer suas escolhas. Segundo Ignarra (2003), as motivações para o turismo podem ser classificadas em quatro categorias: físicas, psicológicas, sociais e culturais. Mas, o que realmente motiva as pessoas à pratica do turismo de contato com a natureza?

Sabino et al. (2012) sugerem que a motivação para a prática do ecoturismo, por exemplo, está relacionada à capacidade que ele possui de 
conduzir o ser humano a sua própria essência. Mendonça e Neiman (2002), por sua vez, acreditam que o aumento da visitação às áreas naturais é um indicativo de que, assim como a arte, as pessoas necessitam do contato com a natureza, sua fonte de vida. Nessa perspectiva, o conceito de biofilia pode trazer subsídios importantes para a compreensão da complexa rede de explicações para motivação à prática do turismo em ambientes naturais. A biofilia pode ser definida como o vínculo inato dos seres humanos com a natureza (WILSON, 1984), ou seja, existe uma tendência instintiva, independentemente do lugar, faixa etária, condição econômica e cultura, para desenvolvermos uma conexão emocional com o mundo natural, seus processos e elementos vivos, e isto é guiado por princípio biológico e ancestralidade evolutiva. Portanto, visitar ambientes naturais ajuda o ser humano a conectar-se com a infinidade de seres vivos e seus hábitats, permitindo o sentimento de afinidade com a biodiversidade (SABINO et al., 2012).

Admite-se, que tais percepções estão relacionadas às experiências vivenciadas em um cenário específico e que, se forem emocionalmente ativas, são capazes de agregar valor em si e imprimir memória aos fatos. Para muitos especialistas, o conhecimento embasado na ciência pode motivar o contato com a natureza, por dispor de informações técnicas e precisas sobre os processos e funcionamento da mesma. No entanto, Soulé (1997) afirma que a diferença entre a atividade científica e a contemplação e apreciação da natureza é uma pedra em que muitos tropeçam e que para os cientistas parece obvio que o conhecimento possa gerar ação. Afirma, ainda, que não é possível conseguir ensinar biofilia somente a partir do raciocínio lógico e argumentos econômicos, sendo necessário adotar outras estratégias para que as pessoas tenham experiências límbicas ou emocionais com a natureza.

É nesse contexto, portanto, que este trabalho analisa a percepção dos visitantes da região turística Caminho dos Ipês, Mato Grosso do Sul, e sua motivação para a prática do turismo em ambientes naturais, buscando compreender se há uma clara percepção dos visitantes sobre o ecoturismo como experiência; se há preocupação com a educação ambiental e comunidades receptoras, pilares do ecoturismo; e se há motivação biofílica e/ou valorização dos serviços ecossistêmicos.

\section{Material e Métodos}

\section{Área de estudo}

A região turística Caminhos dos Ipês, assim denominada pelo mapeamento e classificação empregados pelo Ministério do Turismo e órgão gestor estadual de turismo, envolve uma área do Cerrado brasileiro integrada por 10 municípios do estado de Mato Grosso do Sul, incluindo a capital estadual Campo Grande. Os mesmos integram duas regiões hidrográficas: bacia hidrográfica do rio Paraná (Nova Alvorada do Sul, Ribas do Rio Pardo) e bacia hidrográfica do Alto Rio Paraguai (Corguinho, Dois 
Irmãos do Buriti, Rio Negro, Rochedo, Terenos). Os municípios de Campo Grande, Jaraguari e Sidrolândia estão inseridos nas duas bacias (Figura 1).

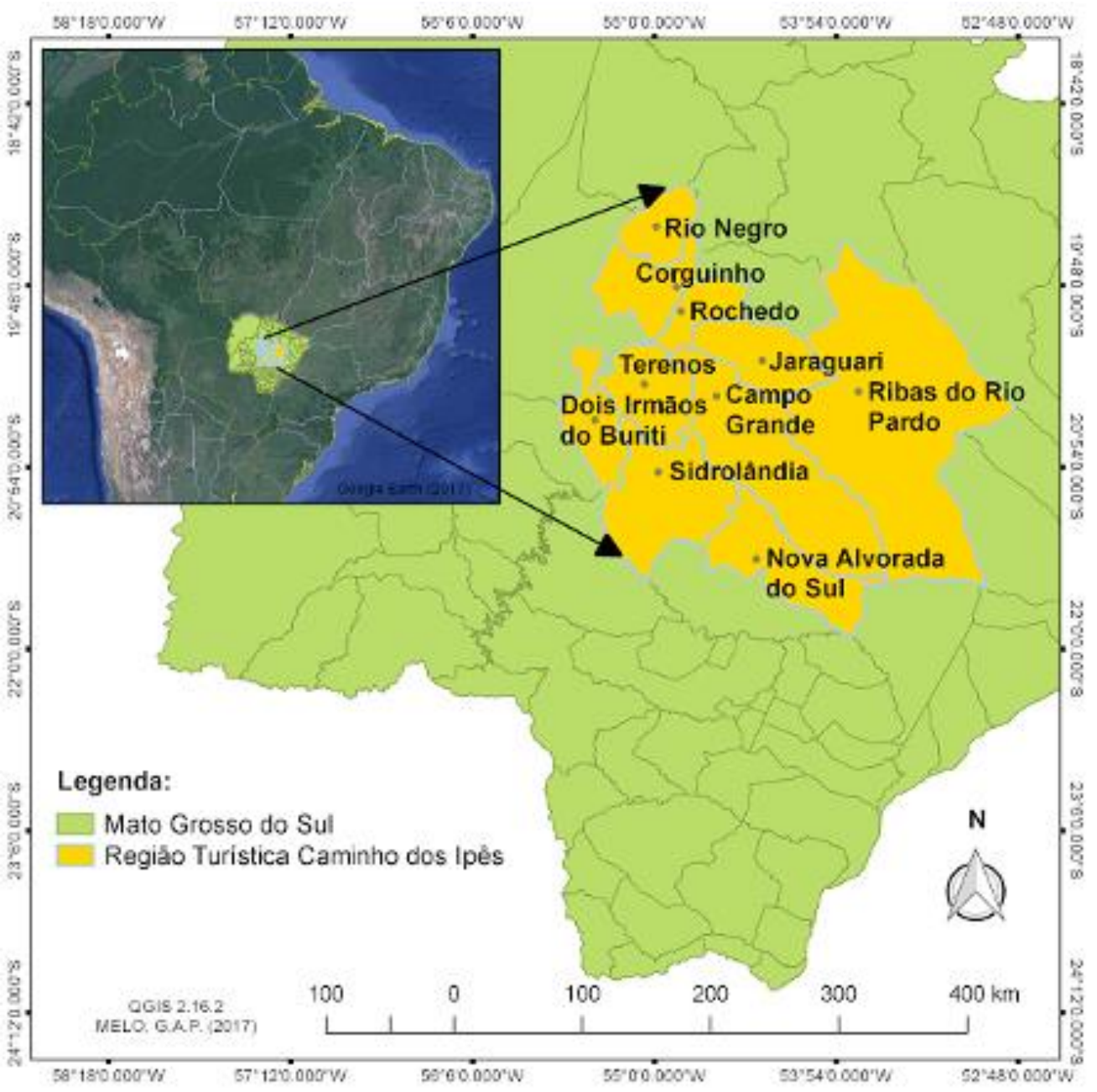

Figura 1: Localização da área de estudo: região turística Caminho dos Ipês - Mato Grosso do Sul, Brasil.

Figure 1: Location of the study area: tourist region Caminho dos Ipês - Mato Grosso do Sul, Brazil.

\section{Métodos}

O trabalho foi realizado no período de maio de 2016 a abril de 2017. Para coleta de dados foi aplicado um formulário semiestruturado junto aos visitantes das áreas naturais da referida região turística. A partir desse formulário, foram registrados dados como: motivação para as práticas na natureza, tipo de atividade desenvolvida, periodicidade de prática ecoturística, indicação de áreas naturais para visitação e comprometimento com a conservação das áreas visitadas. Os dados foram analisados qualitativa e quantitativamente. 


\section{Resultados e Discussão}

\section{Perfil dos visitantes da região turística Caminho dos Ipês e municípios mais visitados}

Ao todo, participaram dessa pesquisa 118 turistas/excursionistas (60,3\% mulheres e 39,7\% homens), originários de 22 cidades brasileiras e de outros dois países: Argentina $(n=2)$ e Bélgica $(n=1)$. Os visitantes brasileiros que estiveram na região turística Caminho dos Ipês pertenciam às seguintes Unidades Federativas: Mato Grosso do Sul (Amambai, Bonito, Campo Grande, Corguinho, Corumbá, Dourados, Douradina, Itaporã, Jardim, Ladário, Miranda, Rio Brilhante e Terenos), Goiás (Chapadão do Céu, Mineiros e Serranópolis), Paraná (Cianorte e Maringá), São Paulo (Americana, Cananéia e São Paulo) e Rio de Janeiro (Areal).

Dentre os turistas que percorreram a região, $49,2 \%$ desenvolvem atividades em ecoturismo periodicamente, 26,3\% raramente e $11 \%$ anualmente. Apenas $2,5 \%$ praticam ecoturismo mensalmente e os que afirmaram praticar ecoturismo diariamente $(2,5 \%)$ atuam como empreendedores ou agentes em ecoturismo. Somente uma pessoa afirma nunca ter praticado atividades ecoturísticas anteriormente.

Observa-se que $95,8 \%$ dos visitantes da região turística Caminho dos Ipês se consideram comprometidos com a valorização das comunidades receptoras, a conservação e proteção das áreas visitadas e 4,2\% não se consideram responsáveis ou comprometidos. As pessoas comprometidas com as áreas visitadas afirmam contribuir com a região turística promovendo educação ambiental, respeitando as áreas visitadas, tendo cuidado com a destinação adequada dos resíduos sólidos, contribuindo na divulgação dos elementos da biodiversidade por meio da produção fotográfica, de vídeos e de diálogos com a comunidade. Além disso, planejam e desenvolvem atividades de baixo impacto ambiental. Um dos entrevistados afirma utilizar resultados de pesquisa científica como ferramenta-base para o ecoturismo e à educação para a sustentabilidade, além de inserir a população local nesse processo. Embora seja esperado atitudes pró-conservacionistas mais expressivas em ecoturistas, estudo conduzido por Beaumont (2011) não apresentou diferença significativa nas atitudes entre ecoturistas e turistas tradicionais.

Apesar do baixo número dos que não percebem a necessidade individual de comprometimento com a conservação dos ambientes visitados, vale reforçar a necessidade de intervenções em educação ambiental junto aos visitantes, seja no receptivo, seja em abordagem feita pelo condutor ou agente de turismo durante os passeios. Os mesmos devem estar dispostos para transformar cada instante em oportunidade educativa. Segundo Hintze (2009), se existe a ausência de preocupação com a educação ambiental, o ecoturismo apenas reafirma as práticas do turismo convencional, pois os visitantes apenas passam pelos lugares e pessoas, como uma forma de lazer, fuga ou válvula de escape à vida cotidiana da cidade.

Os municípios mais visitados para a prática de ecoturismo foram: Campo Grande (60,5\%), Corguinho (28,9\%), Terenos (18,4\%) e Rio Negro 
$(16,7 \%)$, respectivamente. Muitos dos participantes $(n=40 ; 33,9 \%)$ tiveram como destino exclusivo o município de Campo Grande, revelando que destes, $57,5 \%(n=23)$ foram, na verdade, excursionistas, uma vez que fizeram passeios com menos de 24 horas de permanência no local de destino e sem se ausentarem do local de residência. Independentemente do local de origem, a maioria dos participantes da amostra visitou-atrativos naturais da capital estadual, com exclusividade ou não ao município ( $n=76$; $64,4 \%$ ). No entanto, moradores de Campo Grande também deixaram de praticar atividades no próprio município $(n=30)$ escolhendo exclusivamente outros destinos da região turística Caminho dos Ipês (Tabela 1).

Tabela 1: Distribuição dos visitantes conforme local de origem e destino para a prática de atividades ecoturísticas na região turística Caminho dos Ipês.

Table 1: Distribution of visitors according to place of origin and destination for the practice of ecotourism activities in the tourist region Caminho dos Ipês.

\begin{tabular}{|c|c|c|c|c|}
\hline \multirow[b]{2}{*}{$\begin{array}{l}\text { Local } \\
\text { origem }\end{array}$} & \multicolumn{3}{|c|}{ Destino } & \multirow[b]{2}{*}{ Tota } \\
\hline & Campo Grande & $\begin{array}{c}\text { Campo Grande } \\
\text { integrado a outros } \\
\text { municípios }\end{array}$ & $\begin{array}{c}\text { Somente } \\
\text { outros } \\
\text { municípios }\end{array}$ & \\
\hline Campo Grande & 23 & 24 & 30 & 77 \\
\hline $\begin{array}{l}\text { Outros } \\
\text { municípios }\end{array}$ & 17 & 12 & 12 & 41 \\
\hline Total & 40 & 36 & 42 & 118 \\
\hline
\end{tabular}

Durante muito tempo Campo Grande foi vista como uma cidade que oferecia turismo de passagem, isto é, representava apenas o local de embarque e desembarque de turistas que dele dependiam para fazer conexão logística para o Pantanal e/ou Bonito, seus principais destinos. No entanto, atualmente existe um fluxo expressivo de visitantes que percorre Unidades de Conservação e outras áreas naturais da cidade em busca de experiências na natureza, seja como turismo de aventura ou ecoturismo. Também fazem aleatória e intuitivamente roteiros integrados com outras áreas naturais da região turística Caminho dos Ipês, em função da proximidade ou motivados pelo reconhecimento da diversidade de atrativos naturais existentes nessa região.

Campo Grande se mostra, portanto, como uma cidade-chave para roteiros integrados na região turística Caminho dos Ipês, seja por sua localização, capacidade logística e de infraestrutura ou riqueza em atrativos naturais. Além disso, os resultados apontam que, atualmente, dispõe de opções que motivam a visitação e permanência, complementando outros roteiros ecoturísticos na região. Isto se deve, provavelmente, ao aumento no número de empreendedores que têm oferecido opções em ecoturismo na capital sul-mato-grossense, à divulgação em mídias diversas sobre as belezas naturais e o potencial turístico em contato com a natureza que 0 município dispõe, e ao interesse espontâneo de moradores e visitantes em buscar roteiros que priorizem o contato com ambientes naturais. Por se 
tratar de uma capital com características interioranas, Campo Grande apresenta remanescentes naturais expressivos que abrigam elevada riqueza em biodiversidade, além de serem acessíveis para visitantes apreciadores da natureza (BENITES et al., 2014). Essa percepção se faz importante para empreendedores, gestores públicos e tomadores de decisão, a fim de que o planejamento urbano incorpore em suas ações, incisiva e explicitamente, a conservação dos ambientes naturais, cujos reflexos incidirão, de forma direta e positiva, na qualidade de vida da população, no turismo, na saúde, na educação e no rendimento econômico.

\section{Roteiros ecoturísticos no Caminho dos Ipês}

Foi possível delinear vários roteiros integrados de ecoturismo na região a partir dos depoimentos, destacando-se alguns mais citados e respectivas atividades (Quadro 1).

Quadro 1: Roteiros integrados de ecoturismo identificados para a região turística Caminho dos Ipês, Mato Grosso do Sul, Brasil.

Box 1: Integrated ecotourism routes identified for the tourist region Caminho dos Ipês, Mato Grosso do Sul, Brazil.

\begin{tabular}{|c|c|c|}
\hline Roteiro & Atrativos & Atividades praticadas \\
\hline Campo Grande - Terenos & 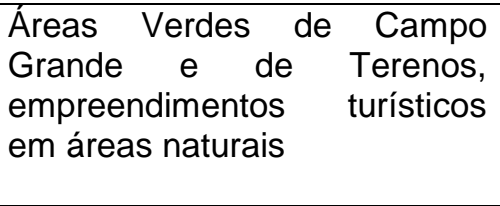 & $\begin{array}{lr}\text { Observação de aves } \\
\text { (birdwatching), fotografia, } \\
\text { turismo de } \\
\text { contemplação } \\
\text { recreação }\end{array}$ \\
\hline Campo Grande - Jaraguari & $\begin{array}{l}\text { Áreas naturais e Comunidade } \\
\text { Furnas do Dionísio }\end{array}$ & $\begin{array}{l}\text { Cicloturismo, } \\
\text { birdwatching, caminhada, } \\
\text { fotografia, Ecoturismo de } \\
\text { Base Comunitária, banho } \\
\text { e recreação }\end{array}$ \\
\hline Campo Grande - Corguinho & $\begin{array}{l}\text { Cachoeira do Ceuzinho e } \\
\text { outras cachoeiras, Morro do } \\
\text { Ernesto, } \\
\text { Ecoturismo Inferninho, } \\
\text { Comunitária na Comunidade } \\
\text { da Boa Sorte, Morro da Boa } \\
\text { Sorte, Cachoeiras de Taboco }\end{array}$ & $\begin{array}{l}\text { Turismo de aventura, } \\
\text { birdwatching, } \\
\text { contemplação, fotografia, } \\
\text { banho e recreação }\end{array}$ \\
\hline $\begin{array}{l}\text { Campo Grande - Rochedo - } \\
\text { Corguinho - Rio Negro }\end{array}$ & $\begin{array}{l}\text { Unidades de Conservação de } \\
\text { C. Grande, Cachoeiras de Rio } \\
\text { Negro, áreas naturais de } \\
\text { Rochedo e de Corguinho }\end{array}$ & $\begin{array}{l}\text { Contemplação, fotografia, } \\
\text { observação da vida } \\
\text { silvestre, birdwatching, } \\
\text { recreação, caminhadas, } \\
\text { rapel }\end{array}$ \\
\hline Campo Grande - Rio Negro & $\begin{array}{l}\text { Áreas naturais de C. Grande, } \\
\text { cachoeira do rio do Peixe, } \\
\text { áreas naturais que seguem } \\
\text { para o Pantanal }\end{array}$ & $\begin{array}{l}\text { Observação de vida } \\
\text { silvestre, birdwatching, } \\
\text { caminhada, } \\
\text { contemplação, } \\
\text { cicloturismo, banho e } \\
\text { recreação }\end{array}$ \\
\hline
\end{tabular}


Nota-se a valorização tanto de elementos naturais quanto de comunidades étnicas, como a Comunidade Quilombola Furnas da Boa Sorte e a Comunidade Quilombola Furnas do Dionísio, localizadas em Corguinho e Jaraguari, respectivamente. Essas comunidades têm 0 desafio de desenvolver Ecoturismo de Base Comunitária (EBC) que valorize a cultura e a biodiversidade de seus territórios, mas ainda enfrentam a falta de apoio e de políticas públicas para esse tipo de turismo.

O cardápio de atrativos presentes nos roteiros demonstra que a região é rica em opções, seja para o visitante regional ou de lugares mais distantes que se interesse pela apreciação da natureza.

\section{As motivações para a prática do ecoturismo no Caminho dos Ipês}

Entre as motivações para a prática do ecoturismo em áreas naturais estão a biofilia e os serviços ecossistêmicos oferecidos pela natureza, ou seja, o quanto a busca, empatia e o contato com os ambientes naturais elevam o espírito humano e são reflexos da presença de biodiversidade e de sua dinâmica natural (MENDONÇA; NEIMAN, 2003; MAYER et al., 2009; GROOT et al., 2010; SABINO et al., 2012; BRATMAN et al., 2012).

O bem-estar derivado de vivências em ambientes naturais foi o motivo mais abordado pelos visitantes para a prática do ecoturismo $(53,4 \%)$, seguido do sentimento de pertencimento à natureza $(50,8 \%)$. Outros elementos como lazer, entretenimento e questões econômicas também foram abordados pelos visitantes, porém de forma menos expressiva, havendo diferença estatisticamente diferente entre os tipos de motivação $\left(X^{2}=55.485 ; g l=4 ; p<0.0001\right)$ (Figura 2).

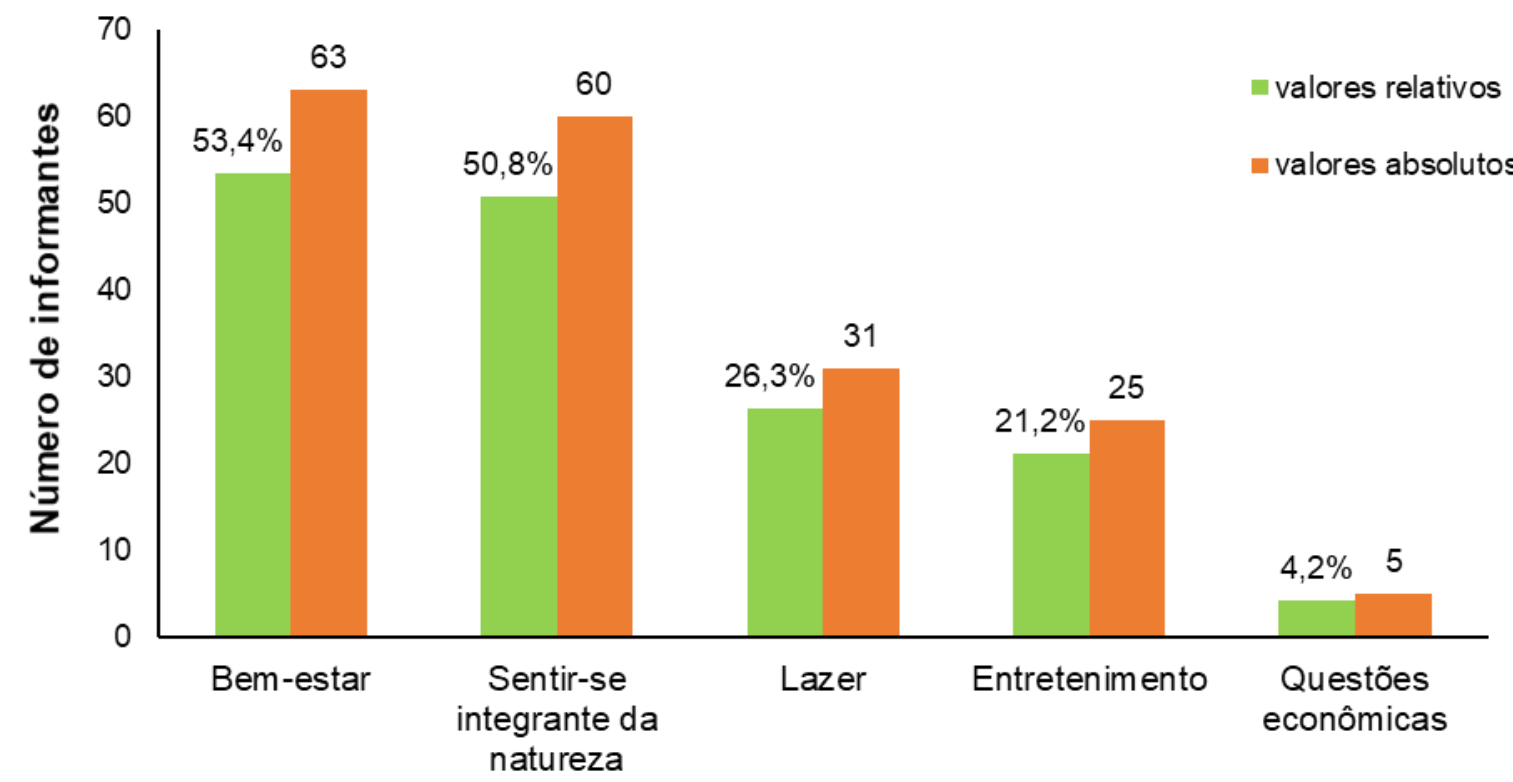

Figura 2: Percepção dos visitantes quanto às motivações para a prática de ecoturismo no Caminho dos Ipês.

Figure 2: Perception of the visitors about the motivations for the ecotourism practice in the Caminho dos Ipês. 
Observa-se a valorização do componente biofílico desses praticantes e o seu potencial para conservação dos ambientes naturais presentes na região turística Caminho dos Ipês. Heinsch (2012) considera que a humanidade evoluiu num panorama natural, portanto a presença de elementos naturais deve desencadear a sensação de bem-estar em nosso organismo, impelindo os humanos a buscarem instintivamente o contato com a natureza em função de bem-estar físico e psicológico.

A perda da biodiversidade ameaça sobremaneira o bem-estar humano, o qual se define como uma experiência humana que inclui bens e materiais básicos para uma vida de qualidade, com liberdade de escolha e de ação, saúde, boas relações sociais, senso de identidade cultural e de segurança, elementos fortemente dependentes de aspectos culturais, geográficos e históricos, determinados por processos econômico-sociais, bem como pela provisão dos serviços ecossistêmicos (DÍAS et al., 2006).

Bem-estar e qualidade de vida estão entre os serviços oferecidos pela natureza, percebidos enquanto valores de amenidade, de uso indireto e/ou como valores de não uso, por questões espirituais, éticas e estéticas. Nisto se apoia a percepção de que a biodiversidade dispõe desde insumos para qualquer tipo de produção de bens materiais, até opções de lazer e serviços variados, o que the imputa alto valor, sendo impossível dissociá-la da vida e convívio humano (ALHO, 2012; CONSTANZA et al., 2014), por isso a tangibilidade monetária e sua aferição nem sempre se aplicam ou se fazem necessárias.

A natureza desempenha importantes funções ao ser humano por meio dos serviços ecossistêmicos. Ecoturismo está ligado aos serviços ecossistêmicos de lazer e recreação, compondo os valores culturais (MACE et al., 2012). De acordo com a Avaliação Ecossistêmica do Milênio da ONU/Millenium Ecosystem Assessment (2005) existe uma classificação para os serviços ambientais, dividindo-os da seguinte forma: serviços de provisão, serviços de regulação, serviços culturais e serviços de suporte (Figura 3, próxima página).

A partir da percepção dos participantes sobre os benefícios das atividades de contato com a natureza correlacionados aos serviços ecossistêmicos foram reconhecidos vários serviços ecossistêmicos (Tabela 2, próxima página). 


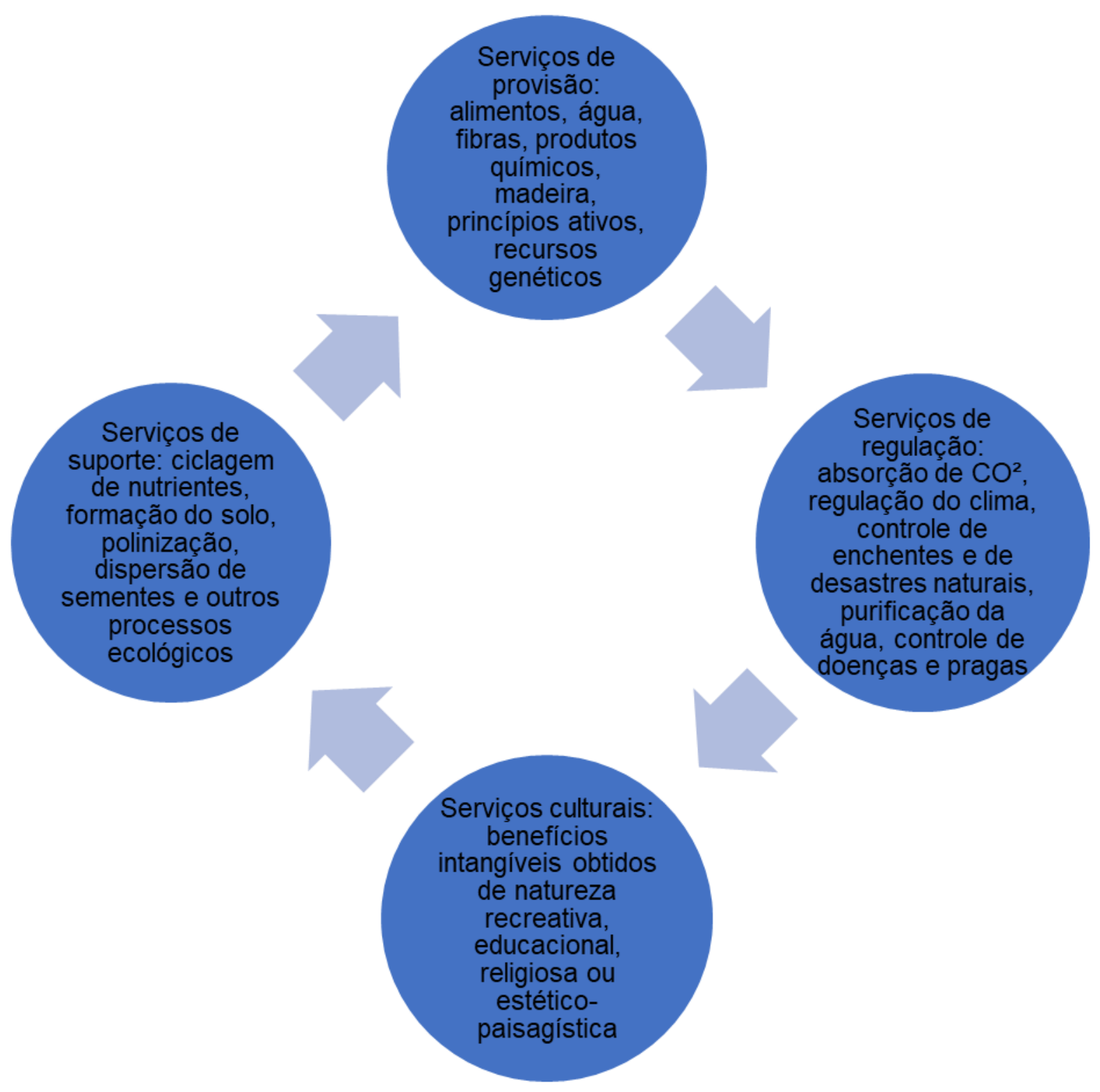

Figura 3: Fluxograma dos serviços ecossistêmicos, conforme a Avaliação Ecossistêmica do Milênio (2005).

Figure 3: Flowchart of ecosystem services, according to the Millenium Ecosystem Assessment (2005).

Algumas transformações comportamentais também foram mencionadas como: desenvolvimento de maior empatia pelas pessoas e pela natureza, estímulo ao cooperativismo e colaboração, melhoria nas relações humanas e na concepção de valores. Antunes e Rabinovici (2010) sugerem que o ecoturismo, ao seguir códigos e princípios éticos, pode contribuir para mudanças estruturantes na sociedade contemporânea. 
Tabela 2: Combinação entre os benefícios identificados pelos participantes da amostra estudada e os serviços ecossistêmicos providos pela natureza. $\mathrm{N}=$ número de respostas colhidas. 1 = serviços de provisão; 2 = serviços de regulação; $3=$ serviços culturais; $4=$ serviços de suporte.

Table 2: Combination of benefits identified by participants in the sample studied and ecosystem services provided by nature. $\mathrm{N}=$ number of responses collected. $1=$ provision services; $2=$ regulation services; $3=$ cultural services; $4=$ support services .

\begin{tabular}{llc} 
Benefícios/percepções & N & Serviços Ecossistêmicos \\
\hline $\begin{array}{l}\text { Sentido de coexistência e interdependência entre } \\
\text { ser humano e outros elementos vivos }\end{array}$ & 47 & $1,2,3$ \\
$\begin{array}{l}\text { Interação com a natureza de forma ativa, } \\
\text { qualificada e real, e sensação de bem-estar }\end{array}$ & 47 & 2 \\
$\begin{array}{l}\text { Redução de estresse e aumento de bem-estar } \\
\text { Oportunidade de admirar as belezas naturais de }\end{array}$ & 43 & 3 \\
perto & 38 & 3 \\
Estímulo à nova visão de mundo & 33 & 3 \\
Possibilidade de orientar e transformar atitudes & 20 & 3 \\
Motivação de vida & 11 & 3 \\
Aversão e medo & 5 & 3 \\
Outros (saúde, tranquilidade, qualidade de vida) & 8 & $1,2,3$ \\
\hline
\end{tabular}

Talvez em escala de ordem de acontecimentos, a biofilia seja a primeira fase, ou seja, deseja-se estar no ambiente natural pela identidade e afinidade inatas com os elementos vivos, mesmo que tais ações sequer sejam conscientes. Depois vem a racionalização: a natureza provê todo tipo de recurso e condição que favorece o bem-estar, por isso, a conservação dos ambientes naturais torna-se importante. Assim, a condição de existência da natureza é prioritária à visão utilitária que ela venha a desempenhar. Mas essa ordem nem sempre pode ser automaticamente presumível, necessitando, muitas vezes, de estímulos. Nessa perspectiva, é importante refletir que apenas sob a ótica dos serviços ecossistêmicos não se valoriza plenamente a biodiversidade, podendo levar a um tipo de vício paradigmático. Uma vez que a sociedade tem forte tendência ao pensamento antropocêntrico, estimular a valorização da biodiversidade apenas por sua utilidade como o ecoturismo, por exemplo, ou porque ela oferece ar puro, pode-se suprimir o valor intrínseco da natureza não observando o princípio ético da existência de vida na Terra e sua continuidade evolutiva. Por essa razão Kopnina (2015), sugere que propostas de conservação devam estar alinhadas em valores inter e transculturais para que se forme uma base de apoio ético mais amplo, em contraste à visão econômica neoliberal e corporativista para a conservação da biodiversidade. Miller et al. (2014), também consideram que os esforços de conservação priorizem a proteção da integridade da biodiversidade e seu funcionamento dinâmico antes dos seus benefícios exclusivos ao ser humano. 
Algumas pessoas afirmaram que embora pratiquem atividades em ambientes naturais, sentem aversão e/ou medo da natureza. Se por um lado existe a biofilia, por outro, há o conceito de biofobia, que se expressa como medo ou aversão aos componentes da natureza, em parte influenciado pelas práticas culturais. Todavia, em se tratando de traço cultural está sujeito a mudanças. Sato e Passos (2011) afirmam que a biofobia é baseada em fundamentos dos sistemas políticos de dominação e exploração, e considera nossa sobrevivência independente dos fatores naturais. Embora tais sentimentos integrem a psicologia humana, o valor de bem-estar e outros benefícios oferecidos pela natureza podem representar uma maneira de estimular a percepção sobre a identidade e conexões com o mundo natural que é comum a outros seres vivos que habitam a biosfera, ampliando, desta forma, o sentimento de pertencimento à natureza ou de biofilia.

Dentre os elementos da biodiversidade que os visitantes reconheceram sentir maior empatia e interesse, independentemente do lugar visitado, foram principalmente plantas, mamíferos em geral, aves e borboletas (Tabela 3).

Tabela 3: Elementos da biodiversidade apontados pelos visitantes como de maior afinidade e interesse para a prática de ecoturismo.

Table 3: Elements of biodiversity pointed out by visitors as having greater affinity and interest for the practice of ecotourism.

\begin{tabular}{lr}
\hline Elementos de biodiversidade & Frequencia mencion \\
\hline Plantas & $50(42,4 \%)$ \\
Mamíferos em geral & $50(42,4 \%)$ \\
Aves & $45(38,1 \%)$ \\
Borboletas & $28(23,7 \%)$ \\
Primatas & $16(13,5 \%)$ \\
Répteis & $15(12,7 \%)$ \\
$\begin{array}{l}\text { Outros (peixes, ser humano, mundo, } \\
\text { todos) }\end{array}$ & $13(11 \%)$
\end{tabular}

De fato, esses grupos são carismáticos e atrativos aos observadores naturalistas (MAMEDE; BENITES, 2008; PIVATTO; GUEDES, 2012). Afinidade com jardins e pomares é parte da cultura humana desde o início da civilização, numa referência à natureza que, segundo Claval (2007), oferece tanto beleza e generosidade quanto a potência de cataclismos, os quais podem, ao mesmo tempo, surpreender as populações e inspirar seus sonhos. Não por acaso, a domesticação de várias espécies vegetais, produção e manutenção de variedades cultivares tiveram ação da ciência e até hoje mobilizam várias áreas do conhecimento científico para seu aprimoramento. Flores e plantas medicinais são destaques nas atividades de observação e vivências na natureza, assim como a flora enquanto componente estruturante da paisagem. Mamíferos e aves são elementos 
tradicionalmente valorizados pelo ecoturismo. No Pantanal Sul, por exemplo, Mamede e Alho (2004) constataram a preferência dos turistas para observação de felinos. Isto demonstra que o lugar exerce influência sobre grupos biológicos de interesse ao observador.

Vale salientar o interesse dos visitantes por grupos de artrópodes como as borboletas e também por outros animais como primatas, répteis e peixes. A prática de observação de vida silvestre tem contribuído para salvaguardar espécies, hábitats, ambientes e regiões sensíveis ou altamente ricas em biodiversidade. O uso sustentável da natureza pelo ecoturismo, isto é, sob determinados critérios e responsabilidade, é considerado importante iniciativa de conservação ao redor do mundo (KRÜGER, 2005; BRIGHTSMITH et al., 2008; BRUMATTI, 2013).

Diante dos resultados, percebe-se que o grupo amostral apresenta afinidade com a prática do turismo em áreas naturais, independentemente dos conceitos de turismo ou excursionismo. Depreende-se, portanto, que a identidade cultural de um grupo social, em suas diferentes escalas, é forjada não apenas pelo conjunto de elementos materiais ou imateriais herdados do passado ou construídos no presente, mas também pelos atributos paisagísticos e elementos da biodiversidade que o ambiente local possui e com os quais os indivíduos convivem permanentemente ou em parte de sua vida, como uma extensão da paisagem cultural. Tais constatações também são reforçadas pela literatura sob o enfoque da psicologia ambiental que aborda como os estímulos físico-químicos e os fatores ambientais contextuais afetam as percepções, as preferências, o conhecimento e as ações refletidas na relação ambiente e comportamento, resultando em comportamentos pró-ambientais (CORRAL-VERDUGO, 2005; FREIRE; VIEIRA, 2006).

\section{Os atrativos naturais da região turística Caminho dos Ipês na percepção dos visitantes}

Os elementos mais atrativos aos visitantes da região turística Caminho dos Ipês foram: riqueza de animais silvestres ( $n=53 ; 44,9 \%$ ), abundância de água $(n=44 ; 37,2 \%)$, as características do bioma Cerrado $(n=43 ; 36,4 \%)$ e o relevo $(n=36 ; 30,5 \%)$.

As características fisiográficas da região turística Caminho dos Ipês relacionadas aos elementos da vegetação, recursos hídricos e relevo, exercem grande apelo à visitação, uma vez que concentram atrativos importantes e decisivos para a escolha dos locais visitados. Morros, vales, cachoeiras, elementos geológicos e geomorfológicos, paisagens, rios de corredeira e biodiversidade abundante costumam ser atrativos para a decisão de roteiros (OLIVEIRA et al., 2007).

Ressalta-se que essa região integra o Cerrado, correspondente a uma das 25 regiões mundiais de importância biológica para a conservação e, ao lado da Mata Atlântica, compreendem os dois hotspots brasileiros que concentram elevada biodiversidade endêmica, com excepcional perda de hábitats restando apenas $20 \%$ da cobertura vegetal original (MYERS et al., 
2000). Embora o Cerrado tenha sido intensamente explorado para produção agropecuária no país e, para alguns, possa parecer tarefa difícil descobrir seus encantos, seus atributos naturais são inúmeros, desde riqueza em águas, paisagens, fauna, flora e demais organismos vivos, além da riqueza cultural de sua gente. Estímulos externos que favoreçam o vínculo vitalício com o Cerrado podem ser fornecidos pelo ecoturismo, enquanto elo entre os desejos de conhecer, pertencer, admirar as belezas naturais que contêm em si e por elas mesmas importância e valor, estando ao alcance de olhos e pensamentos que as estimem (MAMEDE; BENITES, 2008).

$\mathrm{O}$ ecoturismo e o turismo vinculado à natureza dependem do estado de conservação dos ambientes naturais. Isto significa que os serviços ecossistêmicos envolvidos neste processo só serão satisfatórios se os elementos naturais estiverem em bom estado de conservação e desfrutando de estabilidade em seus processos ecológicos.

\section{As práticas ecoturísticas desenvolvidas na região turística Caminho dos Ipês}

As práticas realizadas pelos turistas nos ambientes naturais visitados foram: contemplação da natureza, fotografia, observação da vida silvestre, caminhada ou trekking, observação de aves, ciclismo, meditação e competição esportiva, havendo diferença estatisticamente significativa entre as atividades praticadas $\left(X^{2}=93.119 ; g l=7 ; p<0.0001\right)$ (Tabela 4$)$.

Tabela 4: Atividades ecoturísticas praticadas por visitantes na região turística Caminho dos Ipês, Mato Grosso do Sul, Brasil.

Table 4: Ecotourism activities practiced by visitors in the tourist region Caminho dos Ipês, Mato Grosso do Sul, Brazil.

\begin{tabular}{ll}
\hline Atividade & Número de respostas obtidas \\
\hline Contemplação da natureza & $56(47,4 \%)$ \\
Fotografia & $46(38,9)$ \\
Observação de vida silvestre & $39(33 \%)$ \\
Caminhanda ou trekking & $39(33 \%)$ \\
Observação de aves & $22(18,6 \%)$ \\
Ciclismo & $8(6,8 \%)$ \\
Meditação & $5(4,2 \%)$ \\
Competição esportiva & $2(1,7 \%)$ \\
\hline
\end{tabular}

Algumas imagens dessas atividades podem ser conferidas a seguir (Figura 4). 

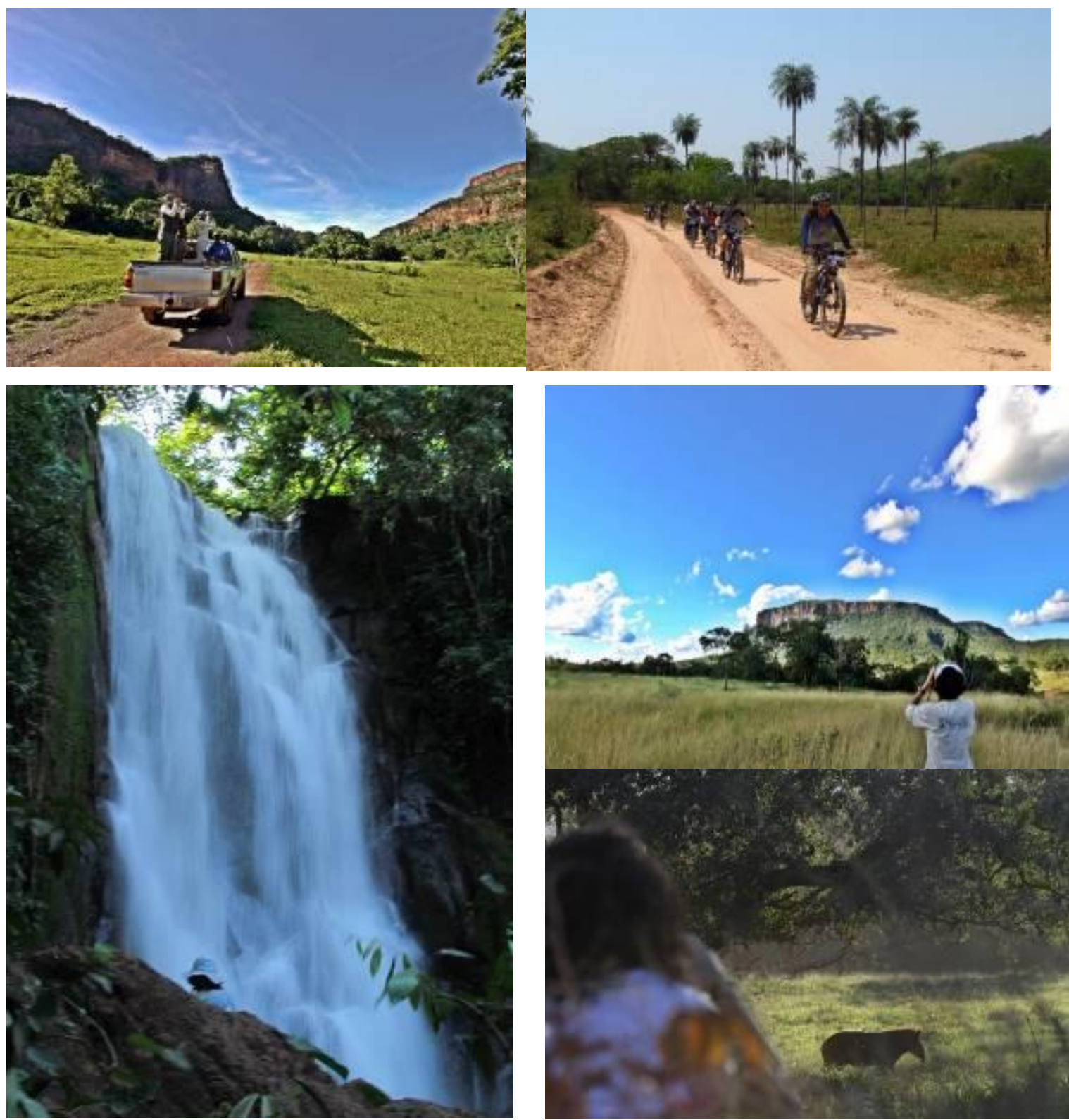

Figura 4: Algumas práticas de ecoturismo na região turística Caminho dos Ipês. Fotos: Simone Mamede e Maristela Benites.

Figure 4: Some ecotourism practices in the tourist region Caminho dos Ipês. Photos: Simone Mamede e Maristela Benites.

Todas as atividades se enquadram nas características de ecoturismo, exceto competição esportiva que, talvez, esteja melhor vinculada ao turismo de aventura na natureza. Para a prática do ecoturismo não é necessário viajar longas distancias para perceber, se perceber no ambiente e usufruir dos elementos naturais. Lançar o olhar a sua volta, valorizar as belezas naturais que o rodeiam, são algumas das possibilidades de ecoturismo local, regional e bem-sucedido (MAMEDE; BENITES, 2008). 


\section{O ecoturismo e a educação ambiental}

Não resta dúvidas que o ecoturismo também representa uma forma de consumo dos recursos naturais. Se praticado de modo inadequado pode inclusive ameaçar os recursos dos quais dependem e são sua motivação (SABINO; ANDRADE, 2003; GEFFROY et al., 2015). No entanto, ao racionalizar que sua constituição e prática estão diretamente vinculados à qualidade e representatividade dos elementos naturais disponíveis, esse segmento turístico pode e deve fomentar e aplicar ações educativas. Ainda que essa identidade esteja implícita no conceito de ecoturismo, é preciso evidenciá-la aos gestores, visitantes e a todos os atores de interesse. Mais que isso, é necessário avançar a etapa do despertamento e da geração de empatia pela natureza para desenvolver ações que, na prática, poderão transformar atitudes e melhorar tanto a interação com o mundo vivo quanto o convívio social humano. Nesse contexto, o educador ambiental, papel assumido por qualquer um dos agentes envolvidos na cadeia produtiva do ecoturismo, é o responsável em delinear e aplicar ações que estimulem reflexões e mudanças de atitude, a fim de tornar as práticas do turismo na natureza como oportunidades efetivamente educativas. A lei federal 9.795/99 (Política Nacional de Educação Ambiental - PNEA) incumbe a todo cidadão a responsabilidade pela educação ambiental, exercendo-a tanto em âmbito formal quando em espaços não formais de educação.

O que debilita, portanto, a capacidade do ser humano compreender e assumir que a natureza é a nossa única identidade e que dela dependemos? Assim, como o ecoturismo pode auxiliar na descoberta de respostas e no direcionamento de soluções? Estas podem ser questões instigadoras a pautarem o desenvolvimento da educação ambiental no ecoturismo.

\section{Conclusões}

Os resultados apontam as práticas de ecoturismo mais viáveis na região turística Caminho dos Ipês, sinalizando, dentre outros aspectos, a existência de demanda principalmente local e regional, o que pode servir de estímulo a políticas públicas e a novos empreendedores nesse segmento turístico. Constata-se também, que a manutenção de áreas naturais gera ativos econômicos para a região, por meio do ecoturismo e excursionismo de mínimo impacto. Com base na percepção dos turistas, o ecoturismo pode ser uma estratégia para gerar e aprimorar o vínculo afetivo com a natureza e contribuir na formação de pessoas mais comprometidas com a conservação dos ambientes naturais e na melhoria das relações humanas, direcionando para a construção de territórios sustentáveis.

Assim, a biofilia estimula o ecoturismo ou seria a valorização dos serviços ecossistêmicos o fator indutor do sentimento de biofilia? Não importa a ordem desses processos e não se pretende atribuir caráter avaliativo dualista ou dicotômico, uma vez que ambos remetem à celebração do mundo vivo e estímulo à sua perpetuidade. A percepção conclusiva deste trabalho é que os diversos elementos da natureza geram benefícios físicos, emocionais e psicológicos ao ser humano, basta usufruí-los de maneira adequada, planejada, ética e sustentável. 


\section{Referências}

ALHO, C. J. R. Importância da biodiversidade para a saúde humana: uma perspectiva ecológica. Estudos avançados, v.26, n.74, p. 151-166, 2012.

ANTUNES, D.M.M.; RABINOVICI, A. Ética e ecoturismo. NEIMAN, Z.; RABINOVICI, A. (orgs.). Turismo e meio ambiente no Brasil. Barueri: Manole, p. 304-323, 2010.

BEAUMONT, N. The third criterion of ecotourism: are ecotourists more concerned about sustainability than other tourists? Journal of Ecotourism, v.10, n.2, p. 135-148, 2011.

BENI, M.C. Como certificar o turismo sustentável? Revista Turismo em Análise, v.14, n.2, p. 5-16, 2003.

BENITES, M.; MAMEDE, S.; SEVERO-NETO, F.; FONTOURA, F.M.; PIVATTO, M.A.C.; HATTORI, H.; ILHA, I.M.N. Guia de Aves de Campo Grande: áreas verdes. Campo Grande: ABF, 2014. 104p.

BRATMAN, G.N.; HAMILTON, J.P.; DAILY, G.C. The impacts of nature experience on human cognitive function and mental health. Ann. N.Y. Acad. Sci., v.1249, p. 118-136, 2012.

BRIGHTSMITH, D.J.; STRONZA, A.; HOLLEC, K. Ecotourism, conservation biology, and volunteer tourism: a mutually beneficial triumvirate, Biological Conservation, v. 141, n.11, p. 2832-2842, 2008.

BRUMATTI, P.N.M. O papel do turismo de observação da vida selvagem para a conservação da natureza. Anais do IX Congresso Nacional de Ecoturismo e do $\checkmark$ Encontro Interdisciplinar de Turismo em Unidades de Conservação. Revista Brasileira de Ecoturismo, v.6, n.4, p.191-206, 2013.

CLAVAL, P. A geografia cultural. Florianópolis: UFSC, 2007.

CONSTANZA, R.; GROOT, R.; SUTTON, P.; PLOEG, S.; ANDERSON, S.J.; KUBISZEWSKI, I.; FARBER, S.; TURNER, R.K. Changes in the global value of ecosystem services. Global environmental change, v.26, p. 152-158, 2014.

CORRAL-VERDUGO, V. Psicologia Ambiental: objeto, "realidades" sócio-físicas e visões culturais de interações ambiente-comportamento. Psicologia USP, v.16, n.1-2, p. 71-87, 2005.

DÍAZ, S.; FARGIONE, J.; STUART CHAPIN, F. III; TILMAN, D. Biodiversity loss threatens human well-being. PLoS Biol, v.4, n.8, p. 1300-1305, 2006.

FREIRE, J.C.; VIEIRA, E. M. Uma escuta ética de psicologia ambiental. Psicologia \& Sociedade, v.18, n.2, p. 32-37, 2006.

GEFFROY, B.; SAMIA, D.S.M.; BESSA, E.; BLUMSTEIN, D.T. How naturebased tourism might increase prey vulnerability to predators. Trends Ecol Evol, v.30, n.12, p. 755-765, 2015.

GROOT, R.S.; ALKEMADE, R.; BRAAT, L.; HEIN, L.; WILLEMEN, L. Challenges in integrating the concept of ecosystem services and values in landscape planning, management and decision making. Ecological Complexity, v.7, p. 260-272, 2010.

HEINSCH, M. Getting down to earth: Finding a place for nature in social work practice. International Journal of Social Welfare, v.21, n.3, p. 309-318, 2012. 
HINTZE, H.C. Ecoturismo na cultura de consumo: possibilidade de Educação Ambiental ou espetáculo? Revista Brasileira de Ecoturismo, v.2, n.1, p.57100, 2009.

IGNARRA, L.R. Fundamentos do Turismo. S. Paulo: Thompson, 2003. 205p.

KOPNINA, H. Revisiting the Lorax complex: deep ecology and biophilia in crosscultural perspective. Environmental Sociology, v.4, p. 315-324, 2015.

KRÜGER, O. The role of ecotourism in conservation: panacea or Pandora's box? Biodiversity \& Conservation, v.14, n.3, p. 579-600, 2005.

MACE, G.M.; NORRIS, K.; FITTER, A.H. Biodiversity and ecosystem services: a multilayered relationship. Trends in Ecology and Evolution, v.27, n.1, p. 1926, 2012.

MAMEDE, S.B., ALHO, C.J.R. Turismo de contemplação de mamíferos do Pantanal: alternativa para o uso sustentável da fauna. IV Simpósio sobre Recursos Naturais e Sócio-econômicos do Pantanal. Anais, Empresa Brasileira de Pesquisa Agropecuária Embrapa-Pantanal, Corumbá, MS. CD-ROM, 2004.

MAMEDE, S.; BENITES, M. Contemplação da fauna no Cerrado brasileiro: uso sustentável para o ecoturismo. In: COSTA, N.M.C.; NEIMAN, Z.; COSTA, V.C. (orgs.). Pelas trilhas do ecoturismo. São Carlos: Rima, p. 217-232, 2008.

MASLOW, A.H. Motivation and personality. New York: Harper and Row, 1954.

MAYER, F. .; FRANTZ, C.M.P.; BRUEHLMAN-SENECAL, E.; DOLLIVER, K. Why is nature beneficial? Environ. Behav., v.41, p. 607-643, 2009.

MENDONÇA, R.; NEIMAN, Z. Ecoturismo: discurso, desejo e realidade. In: ZYSMAN, N. (org.). Meio ambiente, educação e ecoturismo. Barueri: Manole, p. 159-175, 2002.

MENDONÇA, R.; NEIMAN, Z. À sombra das árvores: transdisciplinaridade e educação ambiental em atividades extra-classe. São Paulo: Chronos, 2003.

MILLENNIUM ECOSYSTEM ASSESSMENT. Ecosystems and human wellbeing: synthesis. Island Press: Washington, DC. 2005.155p. Disponível em: $<$ https://www.millenniumassessment.org/documents/document.356.aspx.pdf >.

Acesso em: 03 nov. 2016.

MILLER, B.; SOULÉ, E.; TERBORGH, J. New conservation' or surrender to development? Animal Conservation, v.17, p. 509-515, 2014.

MYERS, N.; MITTERMEIER, R. A.; MITTERMEIER, C.G.; FONSECA, G.A. B.; KENT, J. Biodiversity hotspots for conservation priorities. Nature, v.403, p. 853858, 2000.

OLIVEIRA, S. N.; CARVALHO JUNIOR, O.A.; MARTINS, E.S.; SILVA, T.M.; GOMES, R.A.T.; GUIMARÃES, R.F. Identificação de unidades de paisagem e sua implicação para o ecoturismo no Parque Nacional da Serra dos Órgãos, Rio de Janeiro. Revista Brasileira de Geomorfologia, v.8, n.1, p.87-107, 2007.

PIVATTO, M.A.C.; GUEDES, N.M.R. Observação de vida silvestre e turismo científico: interagir e conservar a natureza. In: SABINO, J. (org.). Ecoturismo nas trilhas da biodiversidade brasileira. Campo Grande: Natureza em Foco, p. 25-40, 2012. 
SABINO, J.; ANDRADE, L. P. Uso e conservação da ictiofauna na região de Bonito, Mato Grosso do Sul: o mito da sustentabilidade ecológica no rio Baía Bonita (Aquário Natural de Bonito). Biota Neotropica, v.3, n.3, p. 1-9, 2003.

SABINO, J.; ANDRADE, L.P.; BESSA, E. Ecoturismo: Valorizar para gerar negócios sustentáveis e renda. In: SABINO, J. (org.). Ecoturismo nas trilhas da biodiversidade brasileira. Campo Grande: Natureza em Foco, p.13-23, 2012.

SATO, M.T.; PASSOS, L.A. Pelo prazer fenomenológico de um não texto. In: GUIMARÃES, M. (org.). Caminhos da Educação Ambiental: da forma a ação. v.l, 5ee Campinas: Papirus, p. 17-30, 2011.

SOULÉ, M.E. Mente na biosfera; mente da biosfera. In: WILSON, E. O. (org.). Biodiversidade. Rio de Janeiro: Nova Fronteira, p. 593-598, 1997.

WILSON, E.O. Biophilia. Cambridge: Harvard University Press, 1984. 283p.

WILSON, E.O. Biodiversidade. Rio de Janeiro: Nova Fronteira, 1997. 657p.

Agradecimentos: Agradecemos a todas as pessoas que se dispuseram a colaborar em nosso formulário de pesquisa. Ao Gleidson Melo pelo auxílio na confecção do mapa. À Uniderp e Capes pela bolsa de pós-graduação concedida à Mamede, S. e Benites, M.

Simone Mamede: Universidade para o Desenvolvimento do Estado e Região do Pantanal, Campo Grande, MS, Brasil.

E-mail: simone.mamede1@gmail.com

Link para o currículo Lattes: http://lattes.cnpq.br/7260694164560471

Maristela Benites: Universidade para o Desenvolvimento do Estado e Região do Pantanal, Campo Grande, MS, Brasil, Brasil.

E-mail: maris.bentes@gmail.com

Link para o currículo Lattes: http://lattes.cnpq.br/7006699867493716

José Sabino: Universidade para o Desenvolvimento do Estado e Região do Pantanal, Campo Grande, MS, Brasil, Brasil.

E-mail: sabino-jose@uol.com.br

Link para o currículo Lattes: http://lattes.cnpq.br/9198286227068321

Cleber José Rodrigues Alho: Universidade para o Desenvolvimento do Estado e Região do Pantanal, Campo Grande, MS, Brasil.

E-mail: alho@unb.com

Link para o currículo Lattes: http://lattes.cnpq.br/3871915319484773

Data de submissão: 26 de outubro de 2017

Data de recebimento de correções: 13 de novembro de 2017

Data do aceite: 13 de novembro de 2017

Avaliado anonimamente 